\title{
Removal of Formaldehyde from Aqueous Solution by Polymeric Resin
}

\author{
Tania Ghumro ${ }^{1}$, Bindia Junejo ${ }^{1}$, Amber R. Solangi ${ }^{1}$ and Saima Q. Memon ${ }^{* 2}$ \\ ${ }^{1}$ National Center of Excellence in Analytical Chemistry, University of Sindh, Jamshoro, Pakistan. \\ ${ }^{2}$ M. A. Kazi Institute of Chemistry, University of Sindh, Jamshoro, Pakistan. \\ *Corresponding Author Email: msaima77@gmail.com \\ Received 06 November 2019, Revised 19 December 2019, Accepted 20 December 2019
}

\begin{abstract}
Formaldehyde (HCHO) is the most common aldehyde in the environment. It is widely present in aquatic and air environment as one of environmental pollutants. It is commonly used for manufacturing building materials and various household products. Now, it has become a matter of concern because it is mutant and carcinogenic, and an irritant to eyes and skin, therefore its removal from water is very important. Adsorption has an edge over the other techniques due to its simplicity, cost effectiveness, less time consuming and environmental friendly behavior. In present study, adsorption efficiency of Amberlite IRA-910 has been examined. Relevant parameters such as $\mathrm{pH}$, adsorbent dose, adsorbate concentration, shaking speed, volume and shaking time have been studied thoroughly. Ultraviolet-visible spectroscopy was used to determine the formaldehyde content in the water. The isothermal study was carried out using the Langmuir, Freundlich and D-R isotherm. Results showed that Amberlite IRA-910 has better adsorption efficiency for the removal of formaldehyde at lower as well as higher concentrations. The thermodynamic and kinetic parameters have also been calculated.
\end{abstract}

Keywords: Formaldehyde, Adsorbent, Adsorption efficiency, Spectrophotometric method

\section{Introduction}

The utmost abundant carbonyl compound in the atmosphere is the formaldehyde (HCHO). It commonly exists in marine and airborne environment such as one of environmental contaminants. Formaldehyde is an irritating, monochrome gas that has a sharp-tasting smell. It is hardly found in its original state as it has a short half-life in air and decays in light to form a poisonous compound. It is commonly used in manufacturing of great number of everyday products. Now, the presence of formaldehyde in atmosphere has become a matter of concern because of its mutant, carcinogenic nature. Therefore, many researchers are dedicating their time to create new advanced technologies for removal of formaldehyde quickly and economically.
The removal of formaldehyde from waste water has been widely studied by applying numerous techniques, including oxidation, reverse osmosis, ion exchange, electro-dialysis, electrolysis, biodegradation and adsorption [1]. But most of them are costly and not simple, some method generate waste product, such as the large amount of sludge is produced by precipitation processes. Reverse osmosis and ion exchange also do not seem to be economically practicable because of their relatively high investment and operational cost [2]. Adsorption is the best waste water treatment method due to many advantages over such as its universal nature, inexpensiveness and ease of operation. Activated carbons (ACs) have been considered for the adsorption of formaldehyde [3-5], intrinsic and Al-doped 
graphene [6], heat-treated rice husks [5], activated carbon fibers (ACFs) [7], karamatsu (Larix leptolepis) bark [8], kaolin and bentonite [9], treated activated carbon and activated alumina [10], activated carbon with addition of $\mathrm{Ag}$ nanoparticle [11] and modified zeolites [12] are reported for formaldehyde removal. We have selected the polymeric resin (Amberlite IRA-910).

Amberlite IR-A910 resin is an effective basic, type 2 , macro reticular anion exchange resin. The fixed porosity of the resin bead structure is significant. It is accurate, discretely porous network which differs entirely from conventional gel type resins, and provides total elimination of large organic molecules throughout adsorption and desorption cycles. It has advanced thermal stability, but is extra sensitive to oxidants specifications. Previously Wawrzkiewicz and Hibachi have used Amberlite IRA-910 for the removal of tartrazine from aqueous solutions [13]. In one more report, Amberlite IRA-910 is used for adsorption of uranium from aqueous solution [14]. Amberlite IRA-910 resin is also applied to immobilize polyacrylamide gel as a selective binding agent (V) [15]. Gold and palladium chlorocomplexes are reported to be adsorbed and separated by Amberlite IRA-910 [16]. Sulphonated azo dyes were adsorbed by Amberlite IRA-910 (Allura Red and Sunset Yellow) from aqueous solutions [13].

In present study, we propose to use Amberlite IRA-910 for the removal of formaldehyde from wastewater. This environmental friendly procedure deals with several advantages including, easy examination and handling, require short time reaction and regeneration of the resin.

\section{Materials and Methods Materials}

Reagents used for this work were analytical or equivalent grade. Amberlite IRA-910 was purchased from Sigma Aldrich (Germany) and then dried at $80{ }^{\circ} \mathrm{C}$ for $1 \mathrm{~h}$ and kept in vaccum dessicator to avoid moisture and contaminants. Formaldehyde $36 \%$ (w/v) was purchased from Merck (Germany. Acetic acid, acetyl acetone, ammonium acetate, hydrochloric acid, sodium hydroxide were purchased from Sigma Aldrich (Germany).

The stock solution (1000 $\mathrm{mg} / \mathrm{L})$ of formaldehyde was prepared by using $36 \%$ formalin solution. Consecutive dilutions were made with their respective stock solutions of formaldehyde in the concentration range $(5-50 \mathrm{mg} / \mathrm{L})$. All the working solutions were prepared from stock solution in deionized water and were wrapperd with aluminium foil and stored at room temperature. $0.1 \mathrm{M} \quad \mathrm{NaOH}$ and $0.1 \mathrm{M} \mathrm{HCl}$ solutions were prepared to adjust $\mathrm{pH}$ of working solutions.

\section{Instrumentation}

WTW inoLab digital $\mathrm{pH}$ meter was used to determine the $\mathrm{pH}$ of sorptive medium. Shaking water bath (wise bath) was used for shaking. Aligent technologies Carry series UV-Visible spectrophotomer was used to determine the absorbance of sorptive medium.

\section{Preparation of Fluoral-p and Formaldehyde- Fluoral-p Complex}

Fluoral-P reagent was prepared in $250 \mathrm{~mL}$ volumetric flask by shaking together $7.7 \mathrm{~g}$ Ammonium acetate, $1.5 \mathrm{~mL}$ of $1.0 \mathrm{M}$ acetic acid, and $1.0 \mathrm{~mL}$ of $1.0 \mathrm{M}$ acetyl acetone, final volume was made up by deionized water. Formaldehyde was added to the Fluoral P solution in a 1:1 volume ratio, formation of yellowish green color indicated the formation of Fluoral P-formaldehyde (3, 5-diacetyl-1, 4- dihydroluthydine (DDL)) [17].

\section{Procedure for Removal of Formaldehyde}

A $10 \mathrm{mg} / \mathrm{L}$ solution of formaldehyde was adjusted at $\mathrm{pH} 2$, weighed amount of adsorbent was added and mixture was agitated at $100 \mathrm{rpm}$ for 30 minutes. Solution was filtered and $\mathrm{pH}$ was adjusted to 6.5 for formaldehyde-Fluoral-p complex formation. A yellowish green complex of Fluoral-P with formaldehyde was prepared in 1:1 volume ratio. Absorbance was measured at $412 \mathrm{~nm}$ [18]. 
The percent sorption (\% A) was calculated by using equation (1).

$$
\% \mathrm{~A}=\left(\left(\mathrm{C}_{\mathrm{i}}-\mathrm{C}_{\mathrm{e}}\right) / \mathrm{C}_{\mathrm{i}}\right) \times 100
$$

\section{Where}

$\mathrm{C}_{\mathrm{i}}(\mathrm{mol} / \mathrm{L})$ is the initial concentration of formaldehyde solution before the adsorption.

$\mathrm{C}_{\mathrm{e}}(\mathrm{mol} / \mathrm{L})$ is the final concentration of formaldehyde solution at equilibrium afterwards the adsorption.

\section{Results and Discussion Effect of Adsorbent Dosage}

Adsorbent dosage is one of the factors which control the adsorption efficiency. The effect of Amberlite IRA-910 for removal of formaldehyde is shown in Fig. 1. The adsorption of formaldehyde registered a slight decrease with increasing amount of polymeric resin. The effect may be explained on the basis that the increase in the adsorbent dose might cause aggregation of adsorbent which in turn decrease the adsorption sites. Therefore, $0.1 \mathrm{~g}$ of Amberlite IRA-910 was selected as an optimal amount for $10 \mathrm{mg} / \mathrm{L}$ formaldehyde elimination at $25^{\circ} \mathrm{C}$.

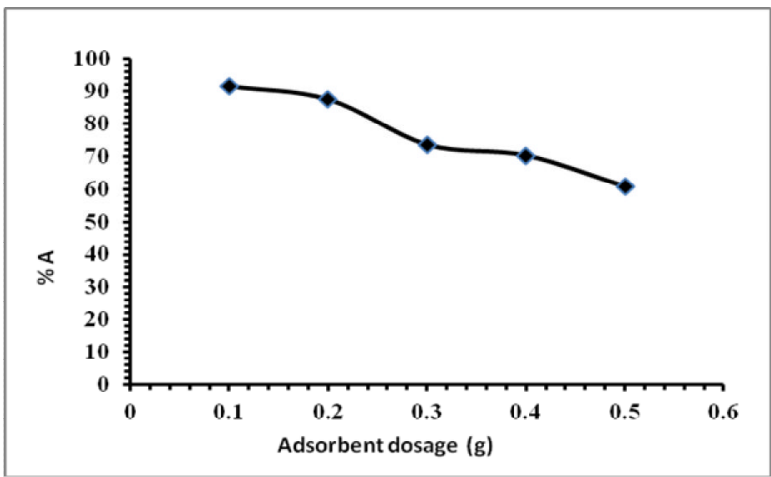

Figure 1. Influence of dosage of polymeric resin on adsorption of formaldehyde $\left(\right.$ Con. $=10 \mathrm{mg} / \mathrm{L}$, shaking time $\left.=30 \mathrm{~min} ; T=25{ }^{\circ} \mathrm{C}\right)$

\section{Effect of $p H$}

To identify the influence of $\mathrm{pH}$, sorption studies were conducted at various $\mathrm{pH}$ values $(2-$ 10). The influence of $\mathrm{pH}$ shows a dynamic part on separation disciplines, as in present readings the polymeric resin was used for adsorption of formaldehyde at fixed concentration. The results achieved are shown in Fig. 2. A slight decrease in $\mathrm{pH}$ can be seen at higher $\mathrm{pH}$ values, $\mathrm{pH} 2$ was selected as optimized for the adsorption of formaldehyde.

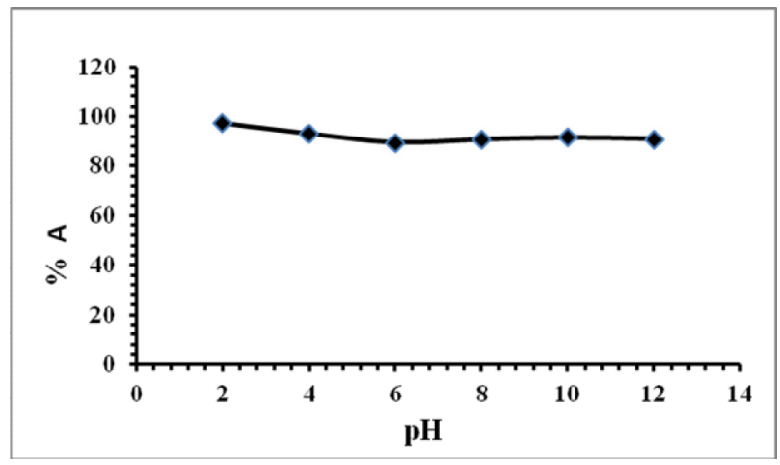

Figure 2. Influence of $\mathrm{pH}$ on adsorption of formaldehyde by polymeric resins $\left(\mathrm{Con} .=10 \mathrm{mg} / \mathrm{L}\right.$, dosage $\left.0.1 \mathrm{~g}, \mathrm{~T}=25^{\circ} \mathrm{C}\right)$

\section{Effect of Shaking Speed}

The impact of shaking speed on the adsorption of formaldehyde through polymeric resin was considered. The shaking speed was studied in the range of 0 to $250 \mathrm{rpm}$, at $\mathrm{pH} 2$, by using $10 \mathrm{~mL}$ of $10 \mathrm{mg} / \mathrm{L}$ formaldehyde solution and $100 \mathrm{mg}$ of adsorbent. Decrease in percentage removal with increasing shaking speed can be seen from Fig. 3. Therefore, all further experiments were carried out at shaking speed of $50 \mathrm{rpm}$.

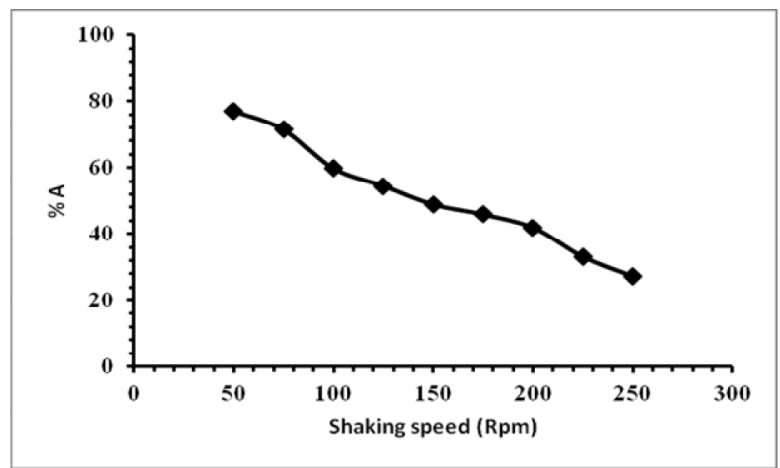

Figure. 3. Influence of shaking speed on the adsorption of formaldehyde by polymeric resins Conc $=10 \mathrm{mg} / \mathrm{L}$, dosage $0.1 \mathrm{~g}$, $\mathrm{T}=25^{\circ} \mathrm{C}, \mathrm{pH}=2$ )

\section{Effect of Volume}

Effect of volume (Fig.4) of formaldehyde solution on removal was studied in range 10 to 60 $\mathrm{mL}$ at optimum $\mathrm{pH}$, shaking speed and amount. A 
decrease in percentage removal was registered with increasing volume.

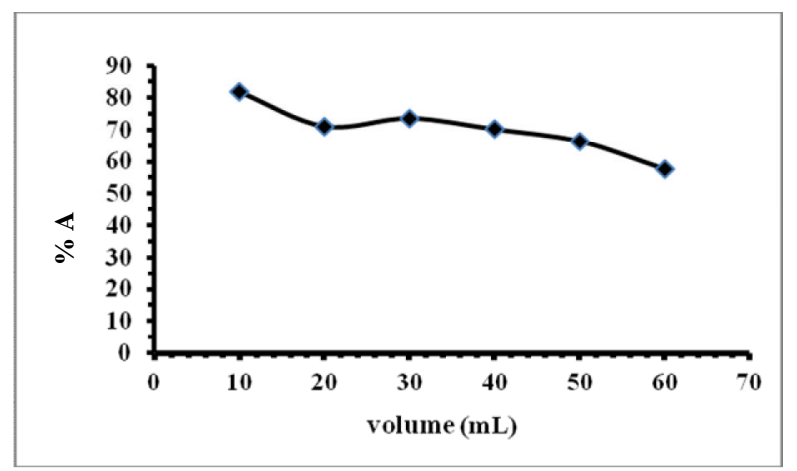

Figure. 4. Influence of volume on adsorption of formaldehyde by polymeric resins $\left(\right.$ Conc $=10 \mathrm{mg} / \mathrm{L}$, dosage $\left.0.1 \mathrm{~g}, \mathrm{~T}=25^{\circ} \mathrm{C}, \mathrm{pH}=2\right)$

\section{Isotherm Study}

The contact of analyte with sorbents can necessarily be defined by analysis of equilibrium data, which support to calculate the adsorption efficiency of the sorbents and understanding into adsorption process [19].

The Langmuir, Freundlich and D-R (Dubinin- Radushkevich) equations eq.2, 3 and 4 respectively were plotted using data obtained from equilibrium experiments over the concentration range of $0.5 \mathrm{mg} / \mathrm{L}$ to $50 \mathrm{mg} / \mathrm{L}$. The sorption experiment for formaldehyde was carried out by agitation of 100-500 mg of adsorbent material at different concentration of formaldehyde for $30 \mathrm{~min}$ at $50 \mathrm{rpm}$ at room temperature.

$$
\frac{\mathrm{C}_{\mathrm{e}}}{\mathrm{Cads}}=\frac{1}{\mathrm{Q}_{\mathrm{b}}}+\frac{\mathrm{C}_{\mathrm{e}}}{\mathrm{Q}}
$$

Where

$\mathrm{C}_{\mathrm{e}}=$ the concentration at equilibrium of adsorbate $(\mathrm{mg} / \mathrm{L}) \mathrm{C}_{\mathrm{ads}}=$ at equilibrium the amount of the adsorbate $(\mathrm{mg} / \mathrm{g})$ adsorbed $\mathrm{Q}=$ concentration quantity of solute corresponding to complete monolayer coverage $\mathrm{b}=$ constant associated to the essential energy of the solute [20].

Exterior heterogeneity of the sorbent are assumed by the initial model that is Freundlich adsorption isotherm. The model is applied to illustrate the adsorption specific for varied external surfaces, with the varied energetic diffusion of energetic positions, laterally with interface amongst adsorbed molecules. The famous expression for the Freundlich model is given as [21].

$\log \mathrm{C}_{\mathrm{ads}}=\log \mathrm{A}+\frac{1}{\mathrm{n}} \log \mathrm{C}_{\mathrm{e}}$

Where

$\mathrm{C}_{\mathrm{ads}}=$ at equilibrium the amount adsorbed $(\mathrm{mg} / \mathrm{g})$

$\mathrm{C}_{\mathrm{e}}=$ the concentration of adsorbate at equilibrium $(\mathrm{mg} / \mathrm{L})$

$\mathrm{A}=$ Freundlich constant associated toward the capability of sorption

$1 / n=$ heterogeneity constant related to capability of adsorption

When $\mathrm{n}<1$ bond energies enhanced with the exterior thickness, if $n=1$, all exterior sites are same, if $n>1$ bond energies decline with the exterior thickness [22]. Linear form of the equation 3 was applied to achieve a Freundlich curve.

The data was best suitable to multilayer isotherm through the value of $\mathrm{R}^{2}$ at 0.9988 . The value of $1 / \mathrm{n}$ is found to be 1.309 . The adsorption capacity was calculated from intercept of the curve and was found to be $168 \mathrm{mg} / \mathrm{g}$.

The characteristics porosity of the material and superficial energy of sorption mostly D-R isotherm is commonly applied [23]. The linear form of equation is given:

$$
\begin{aligned}
& \text { Ln } C_{a d s}=\ln X_{m}-\beta \varepsilon^{2} \\
& \varepsilon=\operatorname{RT} \operatorname{In}\left(1+1 / C_{\downarrow e}\right)
\end{aligned}
$$

$\mathrm{E}=\frac{1}{\sqrt{-2 \beta}}$

$E=$ is equal to Polanyi potential

$\mathrm{T}=$ temperature

$\mathrm{R}=$ universal gas constant in $\mathrm{kJ} / \mathrm{mol} / \mathrm{K}$

$\mathrm{C}_{\mathrm{ads}}=$ sorbed quantity of metal ion

$\mathrm{X}_{\mathrm{m}}=$ over-all sorption capability

$\beta=$ the coefficient activity, having dimensions of energy. 
Energy of adsorption was calculated from DR curve and was found to be $8.951 \mathrm{KJ} / \mathrm{mol}$ which indicated that the reaction may favors the ion exchange mechanism [24].

The adsorption isotherm parameters for all three models for the removal of formaldehyde from waste water are given in (Table 1).

Table 1. Freundlich, Langmuir and D-R parameters for formaldehyde on polymeric resin.

\begin{tabular}{|c|c|c|c|c|c|c|c|}
\hline \multicolumn{3}{|c|}{ Langmuir } & \multicolumn{2}{|c|}{ Freundlich } & \multicolumn{3}{|c|}{ D-R } \\
\hline$\underset{(\mathrm{mol} / \mathrm{g})}{Q}$ & $\begin{array}{c}B \\
(\mathrm{~mol} / \\
\left.\mathrm{dm}^{3}\right)\end{array}$ & $\boldsymbol{R}_{L}$ & $\begin{array}{c}A \\
(\mathrm{mmol} \\
/ \mathrm{g})\end{array}$ & $1 / n$ & $\bar{\beta}$ & $\begin{array}{c}X m \\
(\mathrm{mmol} / \mathrm{g})\end{array}$ & $\begin{array}{c}E \\
(k J / m o l)\end{array}$ \\
\hline $\begin{array}{c}4.39257 \\
\text { E-05 }\end{array}$ & 1258.8 & 1.0079 & 5.6543 & 1.309 & -0.0142 & 8.3001 & 8.9515 \\
\hline
\end{tabular}

\section{Thermodynamic Studies}

Thermodynamic parameters of adsorption process were evaluated by conducting adsorption experiments at different temperatures. Thermodynamic parameter such as change of enthalpy $(\Delta \mathrm{H})$, the change of Gibbs free energy $(\Delta \mathrm{G})$, and change of entropy $(\Delta \mathrm{S})$ were calculated from the obtained data using eq. 7-9.

$\Delta G=-R T \ln K_{c}$ (Gibb's Equation)

$$
\mathrm{K}_{\mathrm{c}}=\frac{\mathrm{F}_{\mathrm{e}}}{1-\mathrm{F}_{\mathrm{e}}}
$$

$$
\mathrm{Lnk}_{\mathrm{c}}=\frac{-\Delta \mathrm{H}}{2.303 \mathrm{RT}}+\frac{\Delta \mathrm{S}}{2.303 \mathrm{R}}(\text { Vant Hoff Equation })
$$

Where $\mathrm{R}$ is general gas constant, $(8.314 \mathrm{~J} / \mathrm{mol} / \mathrm{K})$ and $\mathrm{T}$ is temperature in kelvin. $\mathrm{F}_{\mathrm{e}}$ is the fraction of analyte at temperature $\mathrm{T} . \Delta \mathrm{H}$ and $\Delta \mathrm{S}$ were calculated through intercept and slopes of the straight graphs of $\operatorname{lnKc}$ against $1 / \mathrm{T}$. The thermodynamic parameters values are specified in (Table 2).When adsorption temperature increase the adsorption efficiency also increased. Therefore it may be concluded that adsorption of formaldehyde on Amberlite IRA-910 surface is endothermic process. These greater values of $(\Delta \mathrm{H})$ indicated the strong chemical interaction between the adsorbent and adsorbate. The negative value of
$\Delta \mathrm{G}$ shows the feasibility and spontaneity of the adsorption process [22, 25].

Table 2. Thermodynamic data calculated for formaldehyde

\begin{tabular}{|c|c|c|c|c|c|c|c|}
\hline & & $\Delta \mathbf{G ~ k}$ & $\mathrm{J} / \mathrm{mole}$ & & & $\begin{array}{c}\Delta \mathbf{H} \\
\mathbf{k J} / \\
\text { mole }\end{array}$ & $\begin{array}{c}\Delta \mathbf{S} \\
\mathrm{kJ} / \\
\text { mole }\end{array}$ \\
\hline $\begin{array}{c}\text { Adsorb } \\
\text { ent }\end{array}$ & $280 \mathrm{~K}$ & $288 \mathrm{~K}$ & $308 K$ & $323 K$ & $333 K$ & \multirow[b]{2}{*}{$\begin{array}{l}1.056 \mathrm{E}- \\
05 \pm 2.8\end{array}$} & \multirow[b]{2}{*}{$\begin{array}{c}5.457 \mathrm{E}- \\
05 \pm 2.2\end{array}$} \\
\hline $\begin{array}{c}\text { Amber } \\
\text { lite } \\
\text { IRA- } \\
910\end{array}$ & 0.0028 & 0.0013 & -0.0021 & -0.0031 & -0.0029 & & \\
\hline
\end{tabular}
adsorption on polymeric resins kinetics studies.

In order to understand kinetics of adsorption process, pseudo-first-order i.e. eq. 10 and pseudo-second-order rate equations (eq. 11) [26] were plotted.

The initial example describing the rate of adsorption in the liquid-solid system is Lagergren equation. This equation has been one of the maximum applied equations [27]:

$\log \left(q_{e}-q_{t}\right)=\log q_{e} \frac{k t}{-2.303}$

Where

$\mathrm{q}_{\mathrm{e}}$ and $\mathrm{q}_{\mathrm{t}}=$ equilibrium adsorption capacities $(\mathrm{mg} / \mathrm{g}), \mathrm{k}_{1}$ is first order rate constant.

Plot of $\log \left(\mathrm{q}_{\mathrm{e}}-\mathrm{q}_{\mathrm{t}}\right)$ verses time is shown in Fig. 5. Lagergren kinetics model do not support the adsorption in case of formaldehyde on Amberlite IRA 910 completely.

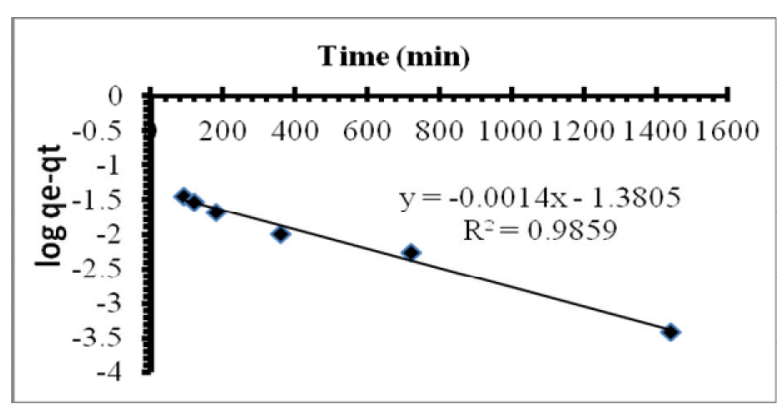

Figure 5. Pseudo first order kinetic model for formaldehyde onto amberlite IRA-910

Pseudo second order rate equation is established on the statement that the adsorption follows second order chemisorption [28]; a 
pseudo-second-order equation established on adsorption equilibrium capability may be stated in the form:

$$
\frac{1}{\mathrm{q}_{\mathrm{t}}}=\frac{1}{\mathrm{k}_{2} \mathrm{q}_{\mathrm{e}}^{2}}+\frac{1}{\mathrm{q}_{\mathrm{e}}}
$$

Where

$\mathrm{k}_{2}$ is constant for 2 nd order rate equation at equilibrium

$\mathrm{q}_{\mathrm{e}}(\mathrm{mg} / \mathrm{g})$ is the amount of formaldehyde adsorbed at equilibrium.

A graph of $t / q_{t}$ vs.t provide a linear correlation for the applicability of the second-order kinetic. The rate constant $\mathrm{k}_{2}$ and $\mathrm{q}_{\mathrm{e}}$ is computed from the slope and intercept of the linear plot. The plot shown in Fig. 6 shows a good correlation value i.e. 0.9975 with initial formaldehyde concentration $10 \mathrm{mg} / \mathrm{L}$. The rate constant value was found to be $-5.8467 \times 10^{-05} \mathrm{~g} / \mathrm{mg}$.min with adsorption capacity of $0.0495 \mathrm{mg} / \mathrm{g}$. This suggests that the pseudo second order model is in best arrangement with investigated data and also well describe the adsorption of formaldehyde onto Amberlite IRA 910.

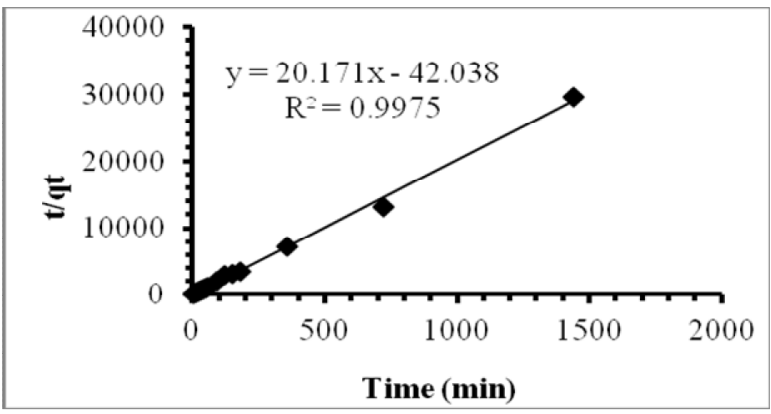

Figure. 6 Pseudo second order kinetic model for formaldehyde onto amberlite IRA-910

Third model of kinetic is intra-particle diffusion that was applied as shown in Fig. 10. This model shows that mass transfer is the ratelimiting mechanism. Mass transfer is defined as the transmission of adsorbate from the aqueous solution into the pores of the adsorbent over its boundary layer. The linear equation of this model is presented below:

$\mathrm{q}_{\mathrm{t}}=\mathrm{R}_{\mathrm{id}} \mathrm{t}^{0.5}+\mathrm{C}_{\mathrm{i}}$
Where

$\mathrm{R}_{\mathrm{id}}=$ intra-particle dispersion rate constant $\left(\mathrm{mg} / \mathrm{g} \cdot \mathrm{min}^{1 / 2}\right)$

$\mathrm{C}$ is the intercept value which offers the information of thickness of the boundary layer $q_{t}$ is sorbed concentration at time ' $t$ '. If the adsorption process follows the intra particle diffusion procedure not only then graph of $\mathrm{qt}$ versus $\mathrm{t}^{1 / 2}$ should be straight but also pass through origin. The Morris and Webber plots of formaldehyde adsorption on Amberlite IRA 910 as shown in Fig. 7 with $\mathrm{R}^{2} 0.9952$ is not passing through origin means diffusion is not the sole rate determining process but the adsorption mechanism is complex in nature.

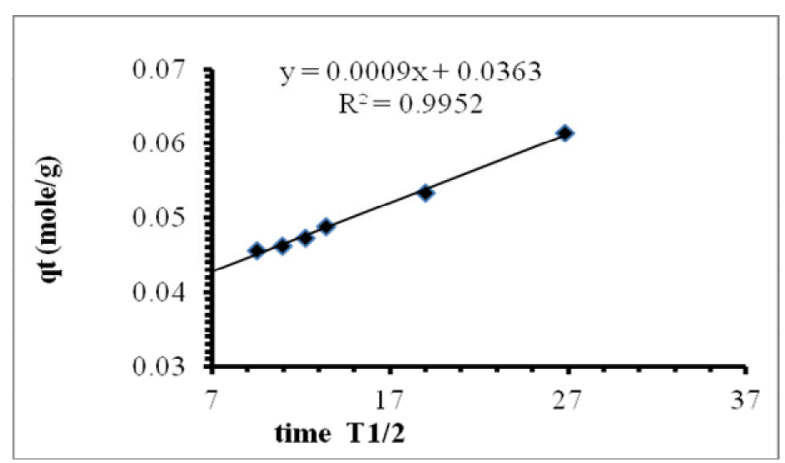

Figure 7. Morris webber model for the sorption of formaldehyde onto amberlite IRA-910

Calculated kinetic parameters for pseudo first-order, second-order and Weber Morris intra particle models for the removal of formaldehyde using polymeric resins (T: $293 \mathrm{~K}, \mathrm{C}: 10 \mathrm{mg} / \mathrm{L}$; sorbent dosage: $0.1 \mathrm{~g}$ ) are shown in Table 3 .

Table 3. kinetic parameters for removal of formaldehyde using polymeric resin.

\begin{tabular}{lcc}
\hline & Pseudo First Order \\
\hline $\mathrm{K}\left(\mathrm{min}^{-1}\right)$ & $\mathrm{q}_{\mathrm{e}}(\mathrm{mg} / \mathrm{g})$ & $\mathrm{R}^{2}$ \\
-0.0032 & 0.3224 & 0.9859 \\
\hline \multicolumn{3}{c}{ Pseudo Second Order } \\
\hline $\mathrm{K}(\mathrm{g} / \mathrm{mg} \cdot \mathrm{min})$ & $\mathrm{q}_{\mathrm{e}}(\mathrm{mg} / \mathrm{g})$ & $\mathrm{R}^{2}$ \\
$-5.8467 \mathrm{E}-05$ & 0.05 & 0.9975 \\
\hline & Morris Weber & \\
\hline $\mathrm{R}_{\mathrm{id}}\left(\mathrm{mg} / \mathrm{gmin}^{1 / 2}\right)$ & $\mathrm{C}$ & $\mathrm{R}^{2}$ \\
0.00092 & 0.0362 & 0.9952 \\
\hline
\end{tabular}




\section{Conclusion}

A simple and fast method for the treatment of formaldehyde contaminated water is developed using commercial polymeric resin Amberlite IRA910. The maximum adsorption efficiency of Amberlite IRA 910 was found to be $95 \%$ at 10 ppm. Higher adsorption efficiency was obtained using $0.1 \mathrm{~g}$ adsorbent dosage of Amberlite IRA910 from $10 \mathrm{~mL}$ of $10 \mathrm{ppm}$ of formaldehyde solution. The Langmuir and D-R isotherms showed good linearity for the equilibrium experimental data with good capacity of formaldehyde removal. In kinetics analysis the pseudo second order model is best fit for adsorption process. The thermodynamic parameters have also been calculated and the positive $\Delta \mathrm{H}$ indicate that adsorption process is endothermic and negative $\Delta \mathrm{G}$ indicate that adsorption of formaldehyde on Amberlite IRA-910 is spontaneous in nature.

\section{References}

1. V. K. Gupta, I. Ali, T. A. Saleh, A. Nayak and S. Agarwal, RSC Adv., 2 (2012) 6380. https://doi.org/10.1039/C2RA20340E

2. T. Viraraghavan and M. M. Dronamraju, $J$. Environ. Sci. Health Part A, 28 (1993) 1261. https://doi.org/10.1080/10934529309375941

3. An. Nihong, Q. Yu, G. Liu, S. Li, M. Jia, and W. Zhang, J. Hazard. Mater., 186 (2011) 1392.

https://doi.org/10.1016/j.jhazmat.2010.12.01

$$
\underline{8}
$$

4. L. Fang, G. Zang and A. Wisthaler, Indoor Air, 18 (2008) 375.

https://doi.org/10.1111/j.16000668.2008.00538.x

5. S. Kumagai, K. Sasaki, Y. Shimizu and K. Takeda, Sep. Purif. Technol., 61 (2008) 398. https://doi.org/10.1016/j.seppur.2007.12.006

6. M. Chi and Y. P. Zhao, Comput. Mater. Sci., 46 (2009) 1085.

https://doi.org/10.1016/j.commatsci.2009.05 .017

7. Y. Song, W. Qiao, S. H. Yoon, I. Mochida, Q. Guo and L. Liu, J. Appl. Polym. Sci., 106 (2007) 2151.

https://doi.org/10.1002/app.26368
8. T. Takano, T. Murakami, H. Kamitakahara and F. Nakatsubo, J. Wood Sci.,54 (2008) 332.

https://doi.org/10.1007/s10086-007-0940$\underline{6}$

9. M. Salman, M. Athar, U. Shafique, R. Rehman, S. Ameer, S. Z. Ali and M. Aeem, Turk. J. Eng. Env. Sci., 36 (2012) 263.

https://doi:10.3906/muh-1109-8

10. M. Agarwal, M. Dave and S. Upadhayay, Curr. World Environ., 6 (2011) 53.

https://pdfs.semanticscholar.org/c287/b9275 693cf92ca25f3fe8f14e21abe73697b.pdf

11. W. D. P. Rengga, M. Sudibandriyo and M. Nasikin, J. Environ. Sci. Eng. Technol., 59 (2016) 04004.

https://doi.org/10.1051/matecconf/20165904 $\underline{004}$

12. D. Paliulis, Pol. J. Environ. Stud., 25 (2016) 251.

https://doi.org/10.15244/pjoes/60727

13. M. Wawrzkiewicz, Environ. Technol., 30 (2009) 1059.

https://doi.org/10.1080/09593330903055650

14. A. Rehmati, A. Ghaemi and M. Samadfam, Ann. Nucl. Energ., 39 (2012) 42.

http://dx.doi.org/10.1016/j.anucene.2011.09. $\underline{006}$

15. A. M. Ralisola, C. A. Suarez, A. A. Menegario, D. Gastmans, C. H. Kiang, C. D. Colaco and R. E. Santelli, Anal.,139 (2014) 4373.

https://doi.org/10.1039/c4an00555d

16. J. M. Sanchez, M. Hidalgo and V. Salvado, Solvent Extr. Ion Exch., 22 (2004) 285. https://doi.org/10.1081/SEI-120030463

17. C. H. Loh. K. W. Chong and M. Ahmed, Anal. Lett., 40 (2007) 281.

https://doi.org/10.1080/00032710600867606

18. H. L. Pinheiro, M. V. de Andrade, P. A. de Paula Pereira and J. B. de Andrade, Microchem. J., 78 (2004) 15.

https://doi.org/10.1016/j.microc.2004.02.017

19. K. Y. Foo and B. H. Hameed, Chem. Eng. J., 156 (2010) 2.

https://doi.org/10.1016/j.cej.2009.09.013

20. K. R. Hall, L. C. Eagleton, A, Acrivos and T. Vermeulen, Ind. Eng. Chem. Fundamen., 5 (1966) 212-223 https://doi.org/10.1021/i160018a011 
21. G. Mckay, H. S. Blair and J. R. Gardner, $J$. Appl. Polym. Sci., 27 (1982) 3043. https://doi.org/10.1002/app.1982.070270827

22. S. I. H. Taqvi, S. M. Hasany and M. I. Bhanger, J. Hazard. Mater., 141 (2007) 37. https://doi.org/10.1016/j.jhazmat.2006.06.08 $\underline{0}$

23. U. A. Qureshi, A. R. Solangi, S. Q. Memon and S. I. H. Taqvi, Arab. J. Chem., 7 (2014) 1166.

https://doi.org/10.1016/j.arabjc.2013.08.018

24. R. Donat, A. Akdogan, E. Erdem and H. Cetisli, J. Colloid. Interf. Sci., 286 (2005) 43.

https://doi.org/10.1016/j.jcis.2005.01.045
25. R. K. Gautam, A. Mudhoo and M. C. Chattopadhyaya, J. Environ. Chem. Eng., 1 (2013) 1283.

https://doi.org/10.1016/j.jece.2013.09.021

26. N. Sivarajasekar and R. Basker, J. Ind. Eng. Chem., 20 (2014) 2699.

https://doi.org/10.1016/j.jiec.2013.10.058

27. S. K. Lagergren, Sven. Vetenskapsakad. Handingarl., 24 (1898) 1. https://ci.nii.ac.jp/naid/10016440244/\#cit

28. A. E. Ofomaja, Chem. Eng. J., 126 (2007) 35.

https://doi.org/10.1016/j.cej.2006.08.022 